\title{
Considerations on the optimization of river information services records Mihai GHIBA ${ }^{1, a}$
}

${ }^{1}$ Department of Engineering and Management of Technological Systems, Faculty of Mechanics, University of Craiova, Calugareni Street 1, 220037, Drobeta Turnu Severin, Mehedinti, Romania

agomog44@yahoo.com

Keywords: RIS services, AIS standard, e-Log Book, e-SRB

\begin{abstract}
This paper makes a comparative analysis of the data recorded and used in inland transport activity using the information recorded in "electronic ship reporting" and in "automatic information service" in the River Information Services - Vessel Traking and Tracing standard. The main objective is the accuracy of records, ensuring their integration through the application of recorded data. Their integration allows the realization of e-LogBook objectives and e-Service Record Book, documents that are currently being used in written form. Thus, the accuracy of information records in electronic documents increases and enables their effective use in the interest of operators, shipowners and crew. Thus, risk factors are diminished in favor of safety factors in terms of crew and ship.
\end{abstract}

\section{Introduction}

This paper aims to analyze RIS records and to assess the evaluation possibilities thereof, based on the principle of one-time data entry through a unique window. Thus, a rigorous control of records is created, which determine complete and quality records, thus the content thereof can be guaranteed. The Directive 2005/44/EC, together with Regulation no. 414/2007 set from the point of view considered in this analysis that:

- the existence on board the ship of the possibility of communication via the internet using GSM connection for electronic reporting of voyage (ERI) is required, see Article 3 pct. 3 of Regulation-414/2007;

- it defines RIS users as skippers, RIS operators, lock operators, waterway authorities, terminal operators, operators in calamity centers, fleet managers, cargo shippers, freight brokers, consignees and supply forwarders according to art. 4.2.5 of the Regulation. From this point we made a matrix of ship records for ERI, RIS component and for AIS, RIS-VTT component.

Since the volume of data covers a large amount, we have reduced the matrix to the titles of record groups, as follows:

Table 1 Group of records

\begin{tabular}{|l|l|c|c|}
\hline No. & \multicolumn{1}{|c|}{ Titles of the group of records } & ERI & AIS \\
\hline 1 & vessel identification data set & $\mathrm{X}$ & $\mathrm{X}$ \\
\hline 2 & voyage data & $\mathrm{X}$ & $\mathrm{X}$ \\
\hline 3 & information on dangerous goods & $\mathrm{X}$ & $\mathrm{X}$ \\
\hline 4 & dynamic information & $\mathrm{X}$ & $\mathrm{X}$ \\
\hline 5 & dimensions of the ship & & $\mathrm{X}$ \\
\hline 6 & data on the position of AIS antenna & $\mathrm{X}$ & $\mathrm{X}$ \\
\hline 7 & dimensions of the ship & $\mathrm{X}$ & $\mathrm{X}$ \\
\hline 8 & displacement & & $\mathrm{X}$ \\
\hline 9 & AIS and radar auxiliary information & & $\mathrm{X}$ \\
\hline 10 & messages transmitted by AIS & $\mathrm{X}$ & $\mathrm{X}$ \\
\hline 11 & general data on ship & $\mathrm{X}$ & $\mathrm{X}$ \\
\hline 12 & record data on owners, charters, operators & & \\
\hline
\end{tabular}




\begin{tabular}{|c|c|c|c|}
\hline 13 & data on the sizes of the vessel or convoy & $\mathrm{X}$ & $\mathrm{X}$ \\
\hline 14 & data on tonnage & $\mathrm{X}$ & $\mathrm{X}$ \\
\hline 15 & data on Engines and Hull & & $\mathrm{X}$ \\
\hline 16 & data on goods & $\mathrm{X}$ & $\mathrm{X}$ \\
\hline 17 & data on the crew and passengers - crew and passenger list & $\mathrm{X}$ & \\
\hline 18 & name of the commander and number of crew and passengers & & $\mathrm{X}$ \\
\hline 19 & additional data on class/ice & & $\mathrm{X}$ \\
\hline 20 & data on voyage incidents & $\mathrm{X}$ & $\mathrm{X}$ \\
\hline 21 & data on voyage diary & $\mathrm{X}$ & $X$ \\
\hline
\end{tabular}

We note that AIS data covers almost all groups of records, except the data on crew that are found in ERI, for each crew member separately. For automatic calculation of training time, is necessary to combine data from position 17 , data on crew-crew list with common data at position 2 , voyage dates, and with those specific to AIS from position 4, dynamic information, navigation time.

We note the repetition of data which, if entered separately can induce errors, generate waste of time and ultimately, guaranteed records to replace written, recorded and signed documents, cannot be made. We also note that:

- permanent data are recorded - these repeat for all the voyages, the information is changing rarely (vessel name, ENI number, etc.);

- there are data that have a rate of change correlated with the voyage (number of barges from the convoy, freight amounts etc.);

- data are recorded dynamically, constantly changing, and continuously updated, based on equipment operation.

Risks assumed for these types of data:

- errors for registration of ERI separately and AIS separately generated by users can alter the validity of the "electronic document" on transport, with all material (financial or physical) consequences resulting from them, for instance, the electronic bill assigned to another ship.

- data with change rate on voyage, are recorded both in ERI and partially in AIS. For ERI, these data are important, since they represent "electronic navigation and transport documents" and for AIS, safety targets in navigation occur (meeting/over-range positioning, gauges of convoys, their speed and their position on electronic maps). It emphasizes safety requirements for vessels that must carry one or more blue cones because it defines safe space to be observed correlated with the type of dangerous goods transported.

The errors in these records may not only lead to partial alteration of transport safety but also increase the risk parameter values at the expense of safety ones.

- dynamic data can be covered by a proper functioning of AIS equipment. The evolution of AIS vector on ECDIS is monitored and they are compared whenever necessary with radar image. If positionings are consistent, errors fall within the accepted precision parameters $(\varphi$, $\lambda$ and speed).

\section{Optimization of the matrix of records}

Given these considerations and the fact that the matrix shows duplicate records in both standards, we suggest:

- the use of a "single window" loading common database of ERI and AIS on a computer installed on board, under the provisions of Regulation EC 414/2007 art. 3.3 of Regulation EC 414/2007.

- writing a program for data loading, capable of:

$\circ$ taking the ship basic data from the national database and compare it with the same recorded data

O recording common data of ERI and AIS specific to voyage, 
O automatically distributing common records by the operation of the "single window" program in ERI and AIS,

$\bigcirc$ taking the records of equipment in the common program in order to complete the electronic log (e-Logbook),

- completing the records validated by users as defined by art. 4.2.5. of Reg. 414/2007 based on controlled access to the database (username and password), acquired on the quality they have in carrying the voyage. Thus, it meets the "quality objective" by checking records and the work of the skipper who enters data through a single option that is then automatically distributed, is simplified.

This approach of using voyage data enables the realization of the electronic onboard Logbook, eLogBook and, as a first result, the achievement of the electronic record of seafarer's service book, electronic Service Record Book, e-SRB. The achievement of these objectives requires:

1. completing and correlating databases by defining fields.

2. defining the way of using data:

a. public data

b. data of controlled used, protected against the uncontrolled access:

- limited access

- conditioned access.

3. defining the criteria of data correlation.

4. defining the concept of single access window for:

a. control of the information inserted,

b. realization of the successively required to avoid double registration or simultaneous registration

c. control of operators's rights of access.

5. defining the structure of databases and the organization thereof.

\section{Conclusions}

Knowing the general expression:

$$
F_{\text {risk }}+F_{\text {safety }}=1
$$

and knowing that :

$$
F_{\text {safety }}=F_{\text {crew }}+F_{\text {ship }}+F_{\text {waterway }}=1-F_{\text {risk }}
$$

where determining the crew safety is achieved by setting a minimum experience, ie of the minimum training time on board the ships in operation, we conclude that the expression

$$
F_{\text {crew }}=k \cdot \frac{t_{\text {actuallyworked }}}{t_{\text {training }}}
$$

tends to 1 when

$$
t_{\text {actuallywo rked }} \rightarrow t_{\text {training }}
$$

thus, under the given conditions (1), it results that $\mathrm{F}_{\text {risk }}$ tends to zero or more specifically to "the minimum acceptable risk" induced by the coefficient $k$. This coefficient depends on the repeatability of threatening situations or accidents due to lack of experience of the crew. Reducing such situations is achieved both through courses and training and through the correct and actual 
registration of the training times of crew members on board the ships, thus the use of e-SRB is welcome. In terms of improving the safety parameters in maritime transport, the $\mathrm{F}_{\text {ship }}$ function need to be controlled so that ships match the safety maximized values. Control may be exercised by developing e-LogBook to register besides the working time necessary to complete the e-SRB, also ship related technical parameters, for example the values of pollutants emitted by the main engines during navigation that are directly related to their maintenance.

\section{References}

[1]****Regulations EC nr.414/ 13 March 2007 concerning technical guidelines for the planning, implementation and operational use of river information services (RIS) to in Article 5 of Directive 2005/44/EC of the European Parliament and of the Council of harmonised river information services (RIS) of river waterways in the Community.

[2]Ghe. I.Cretu - Optimizing water management systems - Facla Publishing House 1980.

[3]M. Ghe.Ghiba -Danube water pollution resulting from naval transport activity - Universitaria Publishing House 2005-ISBN 973-742-031-4.

[4]M. Ghe. Ghiba - Improving risk control parameters through selective collection and quantified parameters efficient communication- Universitaria Publishing House - ISBN 978-606-14-0562-6 Craiova Romania 2012, pp.217-220.

[5]****Directive 2005/44/EC of the European Parliament and of the Council - of harmonised river information services (RIS) on inland waterways in the Community-OJ L 255-30 ${ }^{\text {th }}$ September 2005.

[6] M. Ghe. Ghiba- Assessment of the risk parameters and their use in the vessel traffic management - Modtech Conferrence 2013.

[7]**** Commission Regulation (EC) No 415/2007 of 13 March 2007 concerning the technical specifications for vessel tracking and tracing systems referred to in Article 5 of Directive 2005/44/EC of the European Parliament and of the Council on harmonised river information services (RIS) on inland waterways in the Community.

[8]**** (EU) Regulation no. 164/2010 of the Commission of 25 January 2010 on the technical specifications for electronic ship reporting in inland navigation referred to in Article 5 of Directive 2005/44 / EC of the European Parliament and of the Council on harmonized river information services (RIS) on inland waterways in the Community. 